\title{
Steroid responsive hypoglycaemia in a patient with spindle cell sarcoma
}

\author{
Emily T. Mudenha, A. Okpe, D. Fernando \\ King's Mill Hospital, Sutton-in-Ashfield
}

\section{Introduction}

We present a case of a gentleman with Non-islet cell Tumor Hypoglycemia (NICTH), a rare cause of spontaneous hypoglycemia that presents clinical challenges in maintaining euglycaemia.

\section{Case report}

A 76 year old gentleman not known to be diabetic presented with confusion and agitation. On admission he had a blood glucose reading of $2.1 \mathrm{mmol} / \mathrm{l}$ and clinical examination confirmed an abdominal mass. He was initially resuscitated with intravenous dextrose but continued to experience hypoglycemic episodes. Urine sulphonylurea, serum insulin, pro-insulin and c-peptide levels tested at the time of hypoglycemia were satisfactory. There was no ketonaemia and the short synacthen test showed adequate response. His IGF 2 and IGF2:IGF1 ratio was elevated. An abdominal Ultrasound and CT scan were inconclusive as to the nature of the mass, so biopsy and histology were organized which confirmed a spindle cell neoplasm. To maintain euglycaemia, he had dietician input for complex carbohydrate meals and regular scheduled snacks, but as this failed to sustain his euglycaemia, he was then started on steroid therapy. He had a good response to the dexamethasone. Unfortunately, as curative therapy of the spindle cell tumor was not an option for him, he was referred for palliative follow-up.

\section{Discussion}

Non-islet cell Tumor Hypoglycemia is a Para neoplastic complication of malignancy resulting from overproduction of incompletely processed insulin-like growth factor (IGF 2) by the tumor, which results in stimulation of the insulin receptors and increased glucose utilization. The IGF 2 also suppresses glucagon and growth hormone release. The aims of treatment in patients with NICTH include maintaining euglycaemia and when possible offering curative therapy for the tumor itself. The usual medical management for spontaneous hypoglycemia in the case of insulinomas has some limited use in NICTH. Steroids are the mainstay of treatment as they are believed to decrease the amount of IGF 2 .

\footnotetext{
CT CAP showing: $6 \times 5.5 \mathrm{~cm}$ mass anterior to acrtic arch and puimonary conus. Large lobulated lesion between liver and right kidney, displacing them both; $26 \times 18 \times 15 \mathrm{~cm}$. Unlikely lymphoma, ?adrenal carcinoma.
}

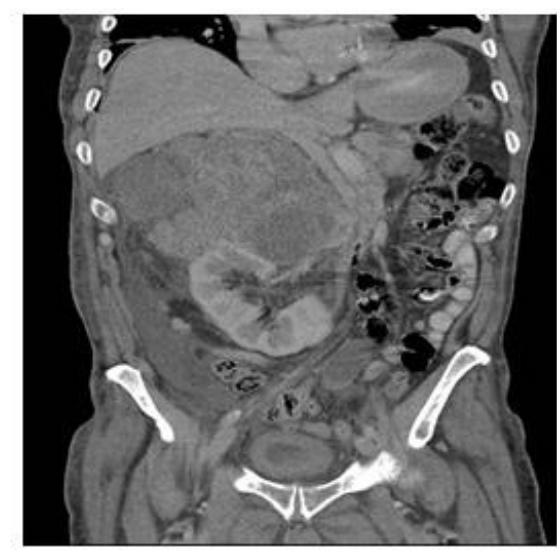

\begin{tabular}{ccc} 
Test & Result & Reference Range \\
\hline Glucose & $2.8 \mathrm{mmol} / \mathrm{L}$ & $3-6 \mathrm{mmol} / \mathrm{L}$ \\
\hline Pro Insulin & 3 & $0-10$ \\
\hline IGF I & $7.7 \mathrm{nmol} / \mathrm{L}$ & \\
\hline IGF II & $123.5 \mathrm{nmol} / \mathrm{L}$ & $11-23 \mathrm{nmol} / \mathrm{L}$ \\
\hline IGF I : IGF II & 16 & $<10$ \\
\hline C Peptide & 0.22 & $0.18-0.63 \mathrm{nmol} / \mathrm{L}$ \\
\hline Cortisol & 229 & $140-690$ \\
\hline
\end{tabular}

